\title{
Um estudo teórico sobre marca-país e sua gestão
}

\author{
Maria Gabriela Montanari e Janaina de Moura Engracia Giraldi ${ }^{1}$ \\ Universidade de São Paulo, FEA-RP/USP, Ribeirão Preto, SP, Brasil
}

DETALHES DO ARTIGO
Histórico do Artigo:
Recebido: 13 de junho de 2017
Revisado: 27 de fevereiro de 2018
Aceito: 28 de abril de 2018
Disponível online em: 01 de maio de 2018
Sistema de revisão "Double blind review"
Editor Científico
Renata Galhanone

\section{Palavras-chaves:}

Marca-país

Country Branding

Imagem de país

\begin{abstract}
RESUMO
Este artigo apresenta um estudo teórico visando esclarecer o conceito de marcapaís, diferenciando-o de imagem de país e efeito país de origem, e também detalhar sua gestão, explorando sua complexidade e suas diferenças em relação à gestão de marcas de produtos e serviços. Fundamentado na literatura, verificouse que a marca-país deriva de um processo gerencial, o country branding (gestão de marca-país), que objetiva diferenciar a nação e suas ofertas no mercado internacional com base em sua cultura. Esse processo engloba desde a criação da marca-país até sua comunicação para os diversos públicos-alvo, é mais complexo do que para produtos e serviços, e deve considerar os elementos de identidade, posicionamento e imagem de país. A imagem de país muitas vezes é o foco das ações de branding, pois consiste nas associações sobre o país que os consumidores internacionais sustentam em sua memória e é avaliada como uma ferramenta fundamental que pode aumentar o poder da marca-país. Assim, foi possível contribuir tanto para a teoria de marca-país e sua gestão, quanto para os governos, fornecendo informações relevantes que auxiliam na delimitação de ações estratégicas em relação à marca-país e a sua imagem.
\end{abstract}

(C) 2018 Internext | ESPM. Todos os direitos reservados!

\section{INTRODUÇÃO}

Dado que a competição por mercados de exportação, recursos humanos qualificados, comércio e domínio internacional continua a crescer entre as nações, tem se tornado indispensável para os países criarem e sustentarem marcas-país fortes (Mugobo \& Wakeham, 2014).

Uma marca-país positiva e poderosa pode fornecer uma vantagem competitiva crucial nessa economia globalizada (Dinnie, 2015) e seu sucesso depende da análise apropriada do trabalho que deverá ser feito em seu processo de elaboração e de um planejamento cuidadoso da estrutura da marca, bem como da comunicação que será adotada (Castro \& Giraldi, 2012).

Esse processo é denominado country branding. Nele, é realizado o gerenciamento dos recursos tangíveis e intangíveis (recursos naturais, cultura, história, sociedade) da nação de forma competitiva (Rojás - Méndez, 2013). Por meio desse processo, a imagem da nação pode ser criada, monitorada, avaliada e gerenciada ativamente para melhorar a reputação do país no mercado internacional (Fan, 2010).

Desta forma, nota-se que o conceito de nação como uma marca é de interesse mútuo entre acadêmicos e profissionais (Hakala, Lemmetyinen \& Kantola, 2013). Esse tema tem despertado cada vez mais interesse de estudos, devido a três pontos: a excitação, a controvérsia e a complexidade (RojásMendez, 2013). A excitação surge como um resultado da limitada teoria que a comunidade acadêmica tem sido capaz de produzir e validar sobre o assunto. A controvérsia está ligada aos diversos pontos de vista e opiniões que surgem e apresentam conflitos sobre 
assuntos públicos e internacionais das políticas dos países. A complexidade decorre dos múltiplos níveis e dimensões que contribuem para o country branding e que vão além do escopo dos produtos e das empresas.

Assim, esse estudo tem como objetivo definir marca-país e diferenciá-la de outros conceitos da literatura de país de origem (imagem de país e efeito país de origem), bem como detalhar a gestão dessa marca, explorando suas principais diferenças em relação à gestão de marcas de produtos e serviços, seus principais objetivos e elementos.

Para isso, é realizado um estudo teórico de caráter exploratório, pois a pesquisa exploratória pode ser utilizada para esclarecer conceitos e aumentar a familiaridade do pesquisador com o problema (Churchill, Brown \& Suter, 2011), o que é necessário neste tema.

Especificamente, esse estudo é caracterizado como uma revisão de literatura, que consiste em avaliações críticas do material que foi publicado, a fim de definir e esclarecer o problema, resumir o estado da pesquisa, identificar relações, contradições, lacunas e inconsistências na literatura, além de sugerir o próximo passo para a solução do problema (Publication Manual of the American Psychological Association, 2010).

Vale destacar que os componentes de revisões de literatura podem ser organizados de várias maneiras, como por exemplo, pela similaridade de conceitos ou teorias, por semelhanças metodológicas entre os estudos revisados, ou ainda de acordo com o desenvolvimento histórico do campo de pesquisa (Publication Manual of the American Psychological Association, 2010).

No caso dessa pesquisa, os seus componentes são agrupados de acordo com suas relações conceituais, visando elucidar a definição de marca-país, conjuntamente com sua gestão (seus objetivos e elementos). Para isso, são investigados nos principais autores de marca e marca-país presentes na literatura e nas principais bases e plataformas científicas: Web of Science, Scopus, Emerald, Elsevier, Google Schoolar, usando como referências as palavras chave: country brand, nation brand, country branding, nation branding, country image, country of origin image. Esses autores são, portanto, selecionados conforme sua quantidade de citações e também de acordo com as suas contribuições teóricas para o esclarecimento dos conceitos de marca-país.

Pretende-se assim contribuir com a teoria de marca-país, esclarecendo e diferenciando conceitos, e também com os governos, fornecendo informações valiosas sobre a complexidade inerente à gestão de marca-país que podem colaborar para o desenvolvimento estratégico de ações para a melhora e a construção dessa marca e de sua imagem.

\section{MARCA-PAÍS}

Segundo a AMA (2007), a marca é um "nome, termo, sinal, símbolo ou design, ou uma combinação de tudo isso, com a intenção de identificar bens e serviços de um vendedor ou grupo de vendedores e para diferenciá-los dos concorrentes". Assim, a chave para criar uma marca, segundo essa definição é encontrar um nome, logotipo, símbolo, desenho de embalagem, ou outro atributo que identifique $\mathrm{o}$ produto e o diferencie dos outros (Keller \& Machado, 2006), ou seja, definir os denominados elementos de marca de forma a diferenciar o produto ou serviço dos concorrentes.

Na prática, a marca é mais que um nome, ela é constituída por um conjunto complexo de imagens, associações, significados, e experiências presentes nas mentes das pessoas (Fan, 2010) e pode ser caracterizada como um produto ou serviço ou empresa considerada em combinação com seu nome, sua identidade e sua reputação (Anholt, 2007). Ela é um conceito intangível que diferencia, reduz a complexidade e simplifica o processo decisório (Kotler \& Pfoertsch, 2008). Logo, marcas bem sucedidas geram vantagens competitivas sustentáveis, e resultados de lucro e desempenho superiores (Chernatony, Malcolm \& Wallace, 2011).

Com a quebra de barreiras internacionais e a alta concorrência por consumidores e investimentos, a gestão de marca se tornou importante tanto para os países quanto para os produtos (Crescitelli \& Giraldi, 2009), isto é, o conceito de marca passou a ser aplicado a uma variedade de objetos, incluindo as nações (Rojas-Méndez, 2013).

De fato, acredita-se que os países sempre foram marcas, mesmo que inconscientemente (Anholt, 2005). A marca-país (Country Brand ou Nation Brand) então pode ser definida como "a combinação única e multidimensional de elementos que proporcionam a nação uma diferenciação e relevância culturalmente 
fundamentada para todos os seus públicos-alvos" (Dinnie, 2008, p.15).

Logo, a marca-país deriva de sua cultura (Dinnie, 2015) e usa elementos de marca como logo, nome, símbolos para essa diferenciação (Pappu \& Quester, 2010). Assim como a marca de produtos e serviços é criada para ser única, competitiva e agregar valor ao cliente, a marca-país busca esses mesmos objetivos, contextualizados para um cenário maior, a nação (Anholt, 2007).

Segundo Fetscherin (2010), a marca-país pertence ao domínio público, é complexa e inclui vários níveis, componentes e disciplinas. Ela engloba a imagem inteira de uma nação, incluindo aspectos econômicos, políticos, históricos e culturais (Fan, 2006; Fetscherin, 2010). As imagens dos países são estímulos importantes para as avaliações por parte dos consumidores, pois elas provocam associações e influenciam decisões de compra não só de produtos, mas de turismo e investimentos (Heslop et. al, 2004; Giraldi, 2016), trazendo poder e valor para a marcapaís.

No entanto, muitas vezes os conceitos se confundem na literatura. Enquanto a marca-país é construída e gerenciada de forma estratégica e intencional e não existe por si só (Knott; Fyall \& Jones, 2015), a imagem de país é formada pelas crenças e impressões que as pessoas têm sobre os lugares, e representam as associações e informações simplificadas que as pessoas fazem sobre um local (Kotler, Haider, Hen, 1993).

Assim como a imagem de marca pode ser definida como "as percepções dos consumidores e preferências por uma marca refletida pelos vários tipos de associações sustentadas na memória dos consumidores" (Keller, 2009, p. 143), a imagem de país abrange um conjunto de associações que liga um dado país a outras informações da memória do consumidor (Giraldi, 2016) e está relacionada à representação mental de um país e sua população, incluindo crenças cognitivas sobre os estágios de desenvolvimento econômicos e tecnológicos do país, além das avaliações afetivas dos seus sistemas sociais e políticos (Wang et. al, 2012). A imagem de um país indica como este é percebido pelos consumidores internacionais, enquanto, por outro lado, a marcapaís se refere a um processo gerencial e estratégico, o country branding (Pappu \& Quester, 2010).

Deste modo, acredita-se que uma imagem bem estabelecida é uma ferramenta benéfica para o country branding (Hakala, Lemmetyinen \& Kantola, 2013). Uma reputação positiva é o resultado esperado desse branding (Knott; Fyall \& Jones, 2015). Entretanto, nem sempre a imagem ajuda na valorização da marca-país. Por exemplo, muitas vezes as pessoas formam a imagem de um país baseadas estereótipos negativos e incoerentes com a realidade deste, criando uma imagem negativa, e assim uma estratégia eficiente de marca deve ser implantada para garantir que essas percepções erradas não afetem o valor da marca-país (Dinnie, 2008).

Além disso, vale destacar que a imagem de país, pode ser usada no processo de criação de marca-país. Nesse ponto, uma etapa necessária no planejamento de marketing de lugares é avaliar a imagem da marca e compreender como ela se compara a imagens concorrentes (Castro \& Giraldi, 2012). Por exemplo, na elaboração do logo e do slogan da marca-país pode-se obter insights sobre os pontos importantes a serem considerados por meio da imagem do país no exterior.

Uma marca-país forte estimula exportações, atrai turistas, investimentos e imigração, e, por consequência, promove o desenvolvimento dos países (Fetscherin, 2010). Por isso, o interesse no tema é cada vez maior, e os estudos apresentam uma tendência crescente nos últimos quinze anos, com o trabalho de vários acadêmicos, como Gilmore (2002), Kotler e Gertner (2002), Papadopoulos e Heslop (2002), Anholt (2005), Fan (2006), Anholt (2007), Dinnie (2008), O'Shaughnessy e O'Shaughnessy (2000), Crescitelli e Giraldi (2009), Fan (2010), Fetscherin (2010), Castro e Giraldi (2012), Dinnie et. al (2010), Pappu e Quester (2010), Rojas- Méndez (2013), Rojás- Méndes, Murphy e Papadopoulos (2013), Mamuti e Özgüner (2014), Matiza e Onu (2014), Mugobo e Wakeham (2014), Knott, Fyall e Jones (2015).

De forma geral, o tema faz parte da área de pesquisa de país de origem, que tem questionado o chamado efeito país de origem, ou seja, tem investigado se o país de origem de um produto influencia ou não as avaliações do mesmo pelos consumidores e consequentemente suas decisões de compra (Andina, Gabriela \& Roxana-Denisa, 2015; Dinnie, 2008; Zeugner-Roth \& Diamantopoulos, 2010).

O efeito país de origem está relacionado à marcapaís e à imagem de país, pois é um fenômeno 
específico de marketing, no qual os consumidores de forma consciente ou subconsciente incorporam um estímulo do país de origem (como por exemplo, o rótulo made in) como um critério avaliativo na formação das suas atitudes em relação a um produto (Bloemer; Brijs \& Kasper, 2009).

Esse estímulo pode ser derivado da imagem de país ou da marca-país. A imagem dos países, por consequências importantes, pois o sucesso (ou a ausência) resultante de um efeito país de origem positivo ou negativo gera mudanças nas condições econômicas, socioculturais e tecnológicas de um país, o que pode afetar as esferas políticas, institucionais, legais, administrativas (Durand, 2016).

As diferenças entre os conceitos apresentados estão ilustradas na Figura 1:

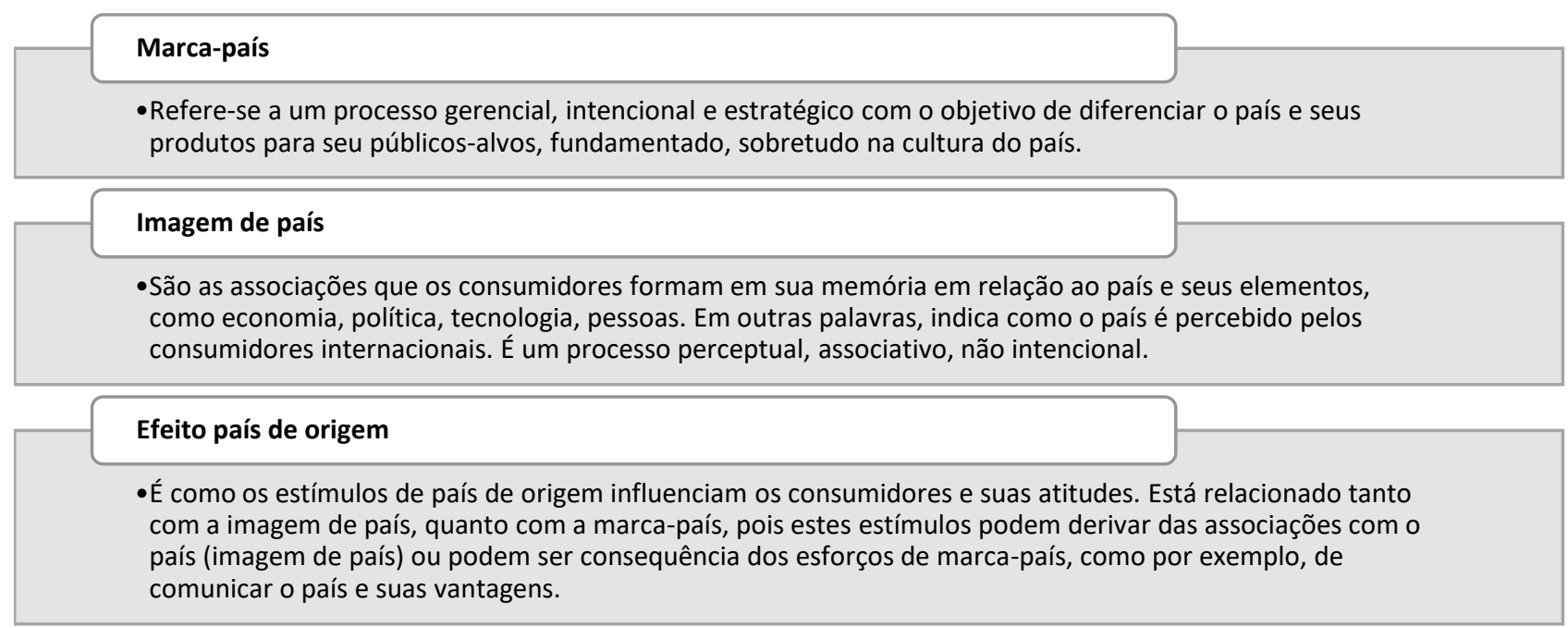

\section{Fig. 1}

Diferenças entre os conceitos de efeito país de origem, imagem de país e marca-país.

Fonte: Elaborado pelas autoras.

exemplo, pode ajudar os gerentes de marketing a desenvolver proposições únicas de venda nas quais eles projetam um rico conjunto de simbolismos e imagens do país sobre os produtos (Brijs, Bloemer \& Kasper, 2011), a fim de afetar diretamente as avaliações, decisões e comportamentos dos consumidores, ou seja, buscando gerar um efeito país de origem.

Vale destacar que esse efeito não ocorre apenas sobre os produtos, como é reportado na maioria dos estudos. O país de origem afeta grandes decisões como: onde as empresas decidem construir suas fábricas, estabelecer suas operações no exterior, comercializar seus produtos, ou terceirizar seus processos (Anholt, 2007), isto é, a simples associação do nome do país reflete sobre os produtos e serviços associados com o país, influenciando também decisões de investir, comprar, viajar, fazer negócios (Giraldi, 2016; Matiza \& Oni, 2014). Logo, o efeito país de origem se dá em relação às inúmeras ofertas do país, que podem ser marcas, produtos, tecnologias, serviços e até organizações (Durand, 2016). Ele tem
Após diferenciar o conceito de marca-país de imagem de país e efeito país de origem, é necessário compreender como essas marcas são gerenciadas.

\section{O PROCESSO DE CONSTRUÇÃO E GESTÃO DE MARCA-PAÍS: O COUNTRY BRANDING}

O branding consiste no planejamento, implantação e controle de um conceito de marca durante a vida da marca (Shimp, 2009). Envolve o processo de dotar os produtos e serviços com as vantagens que se obtêm para a construção de uma marca forte, como por exemplo, lealdade aumentada e preços premium (Keller, 2003). É uma forma poderosa de diferenciação (Pappu, Quester \& Cooksey, 2005).

O foco do branding tanto em produtos quanto em serviços é o mesmo: construir e alavancar o valor da marca (brand equity) a fim de construir uma relação forte entre a marca e seus clientes (Kimpakorn \& Tocquer, 2010). Para Keller (1993), a chave para aumentar o valor da marca é o conhecimento, formado pela consciência de marca (reconhecimento e lembrança da marca) e pela imagem da marca (associações relacionadas à marca), o que implica que 
esse valor ocorre quando o cliente é familiarizado com a marca e possui associações fortes, favoráveis e únicas em sua mente, o que gera uma resposta diferente ao marketing da marca. Já Aaker (1992) coloca que o valor de marca se reflete na preferência global pela marca ao invés de alternativas similares, e cinco ativos são a fonte da criação desse valor e dessa preferência: lealdade à marca, consciência do nome da marca, qualidade percebida da marca, associações com a marca e outros ativos de propriedade, como patentes, relacionamentos nos canais.

Keller e Machado (2006) afirmam que apesar de ter ocorrido um crescente reconhecimento do valor das marcas, as práticas de marketing se tornaram mais complicadas e existem muitos desafios para os gestores de marca, decorrentes de clientes mais bem informados, linhas de marcas mais complexas, amadurecimento de mercados, concorrência crescente e mais sofisticada, dificuldade de diferenciação, redução da fidelidade à marca.

Esses desafios, principalmente aqueles relacionados com a concorrência, com a diferenciação e com as novas opções de comunicação, evidenciam que o branding é importante também para os países. Logo, o country branding refere-se à estratégia de utilizar os elementos do branding como o nome, o logo, entre outros, com o propósito de criar uma identidade distinta para o país em questão, de forma a distinguilo, assim como suas ofertas, nos mercados-alvo internacionais (Pappu \& Quester, 2010).

O country branding se baseia na premissa da aplicação prática do marketing e táticas de branding, buscando criar uma proposição de valor para uma nação e influenciar positivamente as percepções relevantes para os públicos-alvos de uma nação (Matiza \& Oni, 2014). Deste modo, ele pode ser compreendido como um processo que envolve desde o planejamento e estruturação da marca de um país, até a sua comunicação para diferentes públicos, usando técnicas e ferramentas como nome, logo e propaganda.

Essas técnicas criam uma diferenciação significativa aos países (Dinnie, 2008), assim como na esfera dos produtos e serviços. Então, este se torna uma ferramenta importante no desenvolvimento e na manutenção do poder de uma nação (Fan, 2010), ou seja, o esforço de gerenciar uma marca-país visa criar e melhorar o valor dessa marca, o denominado country equity, composto por dimensões de consciência, associações, qualidade percebida e lealdade em relação ao país (Pappu \& Quester, 2010).

Nesse ponto, vale ressaltar que a atividade central do country branding é a gestão da imagem do país (Knott, Fyall \& Jones, 2015), isto é, o country branding se preocupa em aplicar técnicas de branding e comunicação de marketing a fim de promover a imagem de um país (Fan, 2006), buscando tanto alterar a imagem que as pessoas no exterior têm sobre a nação, quanto alinhar essa imagem à realidade (Fan, 2010), além de gerenciar a imagem e reputação do país internamente (Matiza \& Oni, 2014).

Ainda, a consciência do país e a qualidade percebida do país devem ser destacadas no branding de países. Especificamente, para que um país tenha valor na mente dos consumidores, estes devem primeiro apresentar alguma consciência deste país (Pappu \& Quester, 2010). Essa consciência indica o conhecimento das pessoas sobre o país e seus produtos e o branding tem que ser uma ferramenta que aumenta essa consciência e altera ou reforça as visões estereotipadas (Hakala, Lemmetyinen \& Kantola, 2013), que estão ligadas diretamente a imagem do país. Já a qualidade percebida pode ser vista como uma maneira de diferenciar os produtos de um país e indicar sua superioridade por terem sido fabricados neste país (Pappu \& Quester, 2010), e é papel do country branding fazer com que o país seja percebido como fabricante de produtos de qualidade, o que pode melhorar tanto a imagem da nação quanto também gerar mais exportações. Por exemplo, não surpreendentemente, muitos governos agem de forma decisiva para manter a reputação de um país em algum setor de produtos, executando leis para o controle de qualidade (como o governo francês com os vinhos) e também agindo contra aqueles imitadores do produto em todo o mundo, como o caso da tentativa do governo britânico de preservar a reputação do uísque escocês (O'shaughnessy \& O'shaughnessy, 2000).

Em geral, para Fetscherin (2010), o country branding, está ligado a quatro campos principais: o marketing e gestão de lugares, o país de origem, a imagem de um país e a imagem dos produtos do país. Para Matiza e Oni (2014), as fundamentações teóricas do country branding decorrem dos campos de país de origem, imagem de país e de produtos, branding de destinos e identidade de país. $\mathrm{Na}$ verdade, o marketing de lugares é uma área mais 
ampla, na qual os princípios podem ser estendidos a qualquer local, inclusive um país. As demais áreas são comuns aos autores, indicando que na verdade o country branding ganhou força com a evolução nas discussões de país de origem e imagem de país, impulsionadas por fenômenos como a globalização.

De fato, Dinnie (2008) afirma que o branding para países surgiu a partir da globalização, da queda das barreiras comerciais e da intersecção entre dois temas: identidade nacional e país de origem. A primeira envolve disciplinas acadêmicas como geografia política, relações internacionais, ciência política, filosofia política, legislação internacional, sociologia, história, enquanto a segunda engloba marketing, comportamento do consumidor, gestão importante desempenhado por três grupos no processo: governo, grupos industriais e empresas individuais (Papadopoulos \& Heslop, 2002), se comparado apenas aos grupos de consumidores e empresas do branding de produtos e serviços (Keller \& Machado, 2006; Fan, 2010).

Logo, para administrar a marca-país deve-se definir e entregar os incentivos e também gerenciar os fatores que podem afetar os compradores, que são: a imagem, as atrações, a infraestrutura e as pessoas e instituições (Kotler, Haider \& Rein, 2006). Deste modo, as principais diferenças entre o branding de produtos e de serviços estão relatadas na Tabela 1:

\begin{tabular}{rll}
\hline & Country Branding & Product/Service Branding \\
\hline Foco & $\begin{array}{l}\text { Alavancar o valor da marca-país, principalmente por meio } \\
\text { da melhora da imagem do país. Também devem ser } \\
\text { gerenciados outros fatores: as atrações, as pessoas e as } \\
\text { instituições. }\end{array}$ & $\begin{array}{l}\text { Alavancar o valor da marca do produto ou } \\
\text { serviço, diferenciando-se dos concorrentes, } \\
\text { aumentando as vendas e desenvolvendo } \\
\text { relacionamentos com o consumidor. }\end{array}$ \\
\hline Diferenciação & Cultura do país. & $\begin{array}{l}\text { Atributos, benefícios (funcionais e } \\
\text { emocionais) do produto ou serviço. }\end{array}$ \\
\hline Stakeholders & Governos, grupos industriais e empresas individuais. & Empresa. \\
\hline Públicos-alvos & $\begin{array}{l}\text { Turistas, investidores, consumidores, possíveis moradores, } \\
\text { empresas. }\end{array}$ & Consumidores (segmento alvo) \\
\hline Envolvidas & $\begin{array}{l}\text { Geografia política, relações internacionais, ciência política, } \\
\text { filosofia política, legislação internacional, sociologia, } \\
\text { história, marketing, comportamento do consumidor, } \\
\text { gestão de comunicação, gestão de marcas, marketing para } \\
\text { exportação. }\end{array}$ & $\begin{array}{l}\text { Marketing, comportamento do consumidor, } \\
\text { gestão de marcas e de comunicação. }\end{array}$ \\
& &
\end{tabular}

\section{Tab. 1}

Diferenças entre o branding para produtos e para países.

Fonte: Elaborado pelas autoras.

de comunicação, gestão de marcas, marketing para exportação.

Assim, é possível notar que a gestão de marca-país (branding) é muito mais complicada do que para bens e serviços (Crescitelli \& Giraldi, 2009), pois é mais amplo que o marketing e o branding tradicional e engloba outros temas, como relações internacionais e diplomacia pública (Anholt, 2007).

Além disso, não é possível aplicar todos os princípios do branding de produtos e serviços para os países porque estes não estão à venda, não são facilmente confundidos um com o outro e não se movimentam tão rápido quanto os bens de consumo (Anholt, 2006). Ainda, o branding para países apresenta dificuldades, como a complexidade e a diversidade de seus públicos: turistas, investidores, moradores (Gilmore, 2002) e como o papel
Em seguida, são detalhados os objetivos do country branding em termos de seus públicos-alvos.

\subsection{Objetivos do country branding}

O country branding deve atrair turistas, estimular investimentos e impulsionar exportações, além de atrair talentos, o que pode ser visto como um objetivo de longo prazo (Dinnie, 2008). Nesse ponto, Anholt (2007) prefere usar o termo competitive identity (identidade competitiva) para descrever a síntese da gestão de marca com a diplomacia pública, com o comércio e com a promoção de investimentos, exportações e turismo.

O turismo se tornou uma indústria global, estável e uma das que mais cresce em termos de rapidez e importância no mundo (Fetscherin, 2010, Herget, Petrů \& Abrhám, 2015), representando 3,1 \% do PIB 
global em 2014, e tendo mais impacto do que alguns dos maiores setores manufatureiros, como o automotivo e o químico (WTTC, 2015), o que torna esse setor chave para a gestão de marca-país, principalmente como meio de promover o desenvolvimento dos países.

No caso dos turistas, um grande desafio da gestão de marca-país já aparece que é a variedade da demanda turística (Nikolova \& Hassan, 2013). Os motivos para essa demanda também são diversos: negócios, lazer, médico, esportivo, culturais (Mugobo \& Wakeham, 2014). Deste modo, os gestores devem compreender que diferentes lugares atraem diferentes turistas (Kotler \& Gertner, 2002), e a partir daí moldar suas estratégias de marca-país.

Deste modo, o ambiente competitivo também precisa ser muito bem analisado, pois os turistas têm inúmeros destinos à sua disposição (Kotler \& Gertner, 2004), incluindo regiões em desenvolvimento, cuja demanda de serviços vem crescendo (Herget, Petrů \& Abrhám, 2015) e esses destinos fazem as mesmas reinvindicações, como a beleza de seus cenários e sua hospitalidade (Dinnie, 2015). Assim, o marketing pode focar, além de fatores como preço, meios de transporte e acomodação, na herança cultural do país de destino: suas pessoas, valores, modo de vida, o que mostra que o país, suas características e seu branding podem em muitos casos ser usados para obter vantagem (Hurn, 2016).

Vale destacar que outro desafio para o turismo é o fato de os produtos turísticos estarem atrelados a serviços, o que confere uma natureza variável a esses produtos, tornando difícil para os órgãos de gestão garantir uma qualidade desses produtos, bem como exercer um controle sobre eles (Blain, Levy \& Ritchie, 2005). Essa natureza influencia a experiência de consumo do turista (Nikolova \& Hassan, 2013), que é difícil de garantir (Blain, Levy \& Ritchie, 2005), mas fundamental para criar uma vantagem competitiva na atração de turistas (Dwyer \& Kim, 2003).

Além disso, o turismo é um setor orientado à imagem (Elliot, Papadopoulos \& Kim, 2011), o que significa que ele pode competir apenas em função da imagem, dado que o destino tem multi atributos (Pike, 2008), o que pode criar dificuldades na promoção de uma imagem única, positiva e forte pelos gestores de branding.

Quanto às exportações sabe-se que a marca-país pode adicionar valor a elas (Brand Finance, 2016), e por isso, as nações por meio de seu country branding, tentam impulsionar os resultados de exportação. Primeiramente, para promover suas exportações, um país deve considerar sua geografia, seus ambientes institucionais e seus recursos quando projeta suas estratégias de country branding e exportação a fim de criar vantagem competitiva no mercado global (Sun, Paswan \& Tieslau, 2016). Deste modo, ele deve enfatizar sua estrutura de comunicação e seu desenvolvimento econômico, uma vez que estes são colaboradores diretos significantes para as exportações (Sun, Paswan \& Tieslau, 2016).

Em segundo lugar, as nações tentam projetar uma imagem ou um conjunto de valores para auxiliá-las a exportar seus produtos e serviços (O'Shaughnessy \& O'Shaughnessy, 2000). Por exemplo, há campanhas para promover exportações como "100\% Café Colombiano" (Papadopoulos, Essoussi \& El Banna, 2016), que usa a imagem da Colômbia como produtora de café de qualidade. Relógios suíços, uísque escocês são outros casos de como as empresas se beneficiam do nome do país para promover seus produtos internacionalmente (Fetscherin, 2010). Nesse ponto, muitas vezes buscase construir uma imagem de um país usando reputações existentes em algumas marcas ou indústrias, e tentando expandir esse efeito sobre outras marcas ou indústrias (Sun, Paswan \& Tieslau, 2016).

Ainda, para organizar essas atividades de branding a fim de gerar exportações, existem as denominadas organizações para promoção de exportações (export promotion organisations - EPOs) (Dinnie et. al, 2010). No Brasil, por exemplo, há a Agência Brasileira de Promoção de Exportações e Investimentos (ApexBrasil), que atua tanto para promover os produtos e serviços brasileiros no exterior quanto para atrair investimentos estrangeiros para setores estratégicos da economia brasileira (Apex-Brasil, 2017). Para alcançar esses objetivos, a Apex-Brasil realiza ações de promoção comercial para valorizar os produtos e serviços brasileiros internacionalmente, além de missões prospectivas e comerciais, rodadas de negócios, apoio à participação de empresas brasileiras em grandes feiras internacionais e visitas de compradores estrangeiros e formadores de opinião para conhecer a estrutura produtiva brasileira entre outras plataformas de negócios que também têm por objetivo fortalecer a marca Brasil (Apex-Brasil, 2017). 
Considerando os investimentos estrangeiros, estes cresceram em proporção e importância desde os anos 50 (Aharoni \& Brock, 2010), e devido aos seus vários benefícios, os países ao redor do mundo competem intensamente por eles (Sirr, Garvey \& Gallagher, 2012).

Neste ponto, a marca-país, quando desenvolvida por meio de um projeto de branding, pode aumentar o investimento estrangeiro no país (Kilduff, Núnez \& Tabales, 2014), sendo mais uma maneira de diferenciar o país no cenário internacional. O country branding é então uma ferramenta para a promoção do país que cria um impacto positivo na atração de investimentos diretos estrangeiros e na posição econômica geral da nação (Mamuti \& Ozguner, 2014). Geralmente, a atração de investimentos é baseada construção da imagem do país como um lugar atrativo para investir, tentando melhorar as percepções dos investidores potenciais e das empresas (Sirr, Garvey \& Gallagher, 2012).

Quanto aos talentos, acredita-se que uma marcapaís forte e positiva traga trabalhadores estrangeiros especializados bem como estudantes de outros países, que vão adquirir experiências no país e compartilhá-las com seus familiares e amigos, que por sua vez vão utilizar essa informação para criar e modelar suas percepções e imagens do país (Kilduff, Núnez \& Tabales, 2014). Logo, a gestão de marcas de uma nação nesse aspecto é importante não só para atrair os talentos, mas para formar a imagem do país na mente dos consumidores internacionais.

Em geral, pode-se notar que esses objetivos do country branding são difíceis de ser alcançados, uma vez que envolvem públicos distintos, e uma cooperação entre empresas, governo e residentes do país.

Ainda, o country branding deve envolver três elementos chave: a identidade, a imagem e o posicionamento da marca-país (Dinnie, 2008), que são tratados no próximo tópico.

\subsection{Elementos do country branding: Identidade, imagem e segmentação e posicionamento}

Assim como o branding dos produtos consiste em construir uma marca baseada na segmentação e posicionamento da marca, na sua identidade (Keller, 1993) e na sua imagem (Roy \& Barnerjee, 2014), o country branding também envolve elementos de identidade de marca-país, imagem de marca-país e segmentação e posicionamento (Dinnie, 2008; Knott, Fyall \& Jones, 2015), discutidos a seguir.

\section{Identidade da marca-país}

A identidade de uma marca é uma série de associações com a marca que o estrategista aspira criar ou manter (Aaker, 1996). É algo construído internamente e emerge unilateralmente de uma organização; o que os gestores querem que a marca represente (Aaker, 2007).

A identidade de marca é um conjunto único de associações que implica em uma promessa aos consumidores (Ghodeswar, 2008) e é constituída pelo que os consumidores veem em sua frente: 0 logo, o slogan, a embalagem e o design do produto (Anholt, 2007), ou em outras palavras, pelo aspecto físico da marca (produto, desempenho e serviços associados), a personalidade da marca, os valores da marca e as suas relações/associações implícitas (Kapferer, 2001).

A identidade fornece direção, propósito e significado para a marca e é constituída por uma identidade fundamental (a essência da marca, a alma da marca, os valores centrais) e por uma identidade estendida (elementos dimensionais) (Aaker, 1996; Aaker, 2007). A identidade fundamental ou central foca em atributos do produto, perfil do usuário, desempenho do produto, enquanto a identidade estendida é centrada na personalidade da marca, relacionamento e associação forte com o símbolo (Ghodeswar, 2008). Uma marca com uma identidade forte assegura razões claras e convincentes para os consumidores a comprarem, bem como oferece uma vantagem competitiva sustentável (Roy \& Barnerjee, 2014).

Da mesma forma, a identidade da marca-país é o que define o que a marca-país é, e está ligada a elementos como sua história, território, esportes, folclore e, portanto, representa a essência da nação (Dinnie, 2008). Para esse autor, essa identidade é construída baseada em alguns componentes da identidade nacional (national identity).

A identidade nacional engloba as características de uma nação sobre as quais seu povo percebe como essenciais duradouras e distintivas da nação no presente, passado e futuro (Fan, 2010). Essa identidade pode ser considerada um processo de elaboração, planejamento e comunicação do nome e identidade de um país, para construir sua imagem e reputação (Hurn, 2016). 
No processo de branding da marca-país, a identidade desempenha um papel importante tanto na criação da marca (Hakala \& Lemmetyinen, 2011), quanto no seu gerenciamento e comunicação. Na construção de suas marcas-país, as diferentes nações enfatizam aqueles componentes e comunicadores de identidade de país que são mais apropriados para alcançar os objetivos de sua marca-país (Dinnie, 2008).

Esses elementos de identidade da marca-país devem mostrar a quão única é essa marca, de maneira a serem utilizados durante o branding para comunicar e divulgar a marca internacionalmente, criando associações nas mentes dos consumidores, e assim uma imagem deste país e de seus produtos, o que é uma ideia similar a de Aaker (1996). Essa diferenciação deve ser baseada na singularidade do lugar: sua cultura, história e povo (Dinnie, 2008).

Assim, entre os aspectos que podem auxiliar na construção da identidade da marca-país estão os códigos de expressão da identidade da marca-país, definidos por Dinnie (2008): a bandeira, a língua, os ícones. Ainda, o logotipo e o slogan da marca-país são os mais visíveis e concretos símbolos visuais e textuais que refletem a complexidade e o significado da marca, também sendo fundamentais para a divulgação e promoção internacional (Mariutti \& Giraldi, 2012). Também se deve contar o nome da marca como fundamental, dado que alguns países são conhecidos por mais de um nome (Dinnie, 2008). Esses elementos de identidade são os mesmos dos produtos e serviços, apenas contextualizados para um cenário mais complexo, o país.

\section{Imagem do país}

Quanto à imagem da marca, ela é definida por Keller (1993, p.3) como "as percepções sobre uma marca refletidas pelas associações mantidas na mente dos consumidores". Ela é algo que representa o que os consumidores pensam sobre a marca e os sentimentos que se destacam quando eles se lembram dela (Roy \& Barnerjee, 2014), como foi visto anteriormente.

No marketing, esse conceito é relacionado, mas diferente do conceito de identidade de marca. Enquanto a imagem da marca são as associações, imagens que realmente são formadas na mente dos consumidores, a identidade de marca é a imagem de marca que o profissional de marketing deseja criar na mente do consumidor (Groonros, 2004). A identidade da marca assim precede a imagem da marca (Pike, 2008), ou seja, a percepção da identidade modela a imagem da marca na mente dos potenciais consumidores e membros do canal (Roy \& Barnerjee, 2014). Além disso, a imagem da marca pode se transformar de tempos em tempos, em contraste com a identidade da marca, que é mais difícil de ser modificada (Kapferer, 2001).

Analogamente para o país, Dinnie (2008) afirma que a imagem do país é consequente da identidade da marca-país. Isso ocorre porque todos os países possuem uma identidade, que carrega associações positivas ou negativas (Gilmore, 2002). Essas associações em relação ao país compõem a sua imagem (Kotler, Haider, Hen, 1993; Giraldi, 2016), e são, portanto, ligadas à sua identidade, que é duradoura. Ainda, a imagem de país também pode se transformar principalmente na presença de grandes eventos, como os Jogos Olímpicos (Papadopoulos \& Heslop, 2002).

A construção da marca engloba criar uma imagem e comunicá-la interna e externamente, fundamentando-se nos valores positivos do país e em percepções relevantes para promover seu desenvolvimento (Domeisen, 2003). Logo, essa imagem deve ser criada e comunicada pelos profissionais de marketing enfatizando estereótipos positivos relacionados à nação e minimizando julgamentos negativos. Neste último caso, eles devem procurar outras formas de compensar a imagem negativa do país, promovendo seus produtos no exterior por meio de outros atributos, como a qualidade e preço dos produtos do país (melhorando essa imagem), ou, no caso de produtos que são projetados e montados em diferentes países, selecionando uma nação para dar ênfase à imagem do país, o que é provável que repercuta de forma mais positiva para o seu mercado-alvo (Laroche et. al, 2005).

Assim, uma imagem bem estabelecida é uma ferramenta benéfica para o branding das nações (Hakala, Lemmetyinen \& Kantola, 2013). Por outro lado, se um país não é bem gerenciado, ele pode ser dominado por uma imagem negativa ou por um estereótipo (Gilmore, 2002).

\section{Segmentação e posicionamento da marca-país}

Além disso, assim como as marcas de produtos segmentam sua base de consumidores, a marca-país deve segmentar seus diferentes públicos visando 
entender as imagens existentes da nação e também desenvolver comunicações para conter percepções negativas e reforçar percepções positivas (Dinnie, 2008). No marketing de lugares, segmentar os mercados alvos é uma tarefa essencial (Hakala, Lemmetyinen \& Kantola, 2013).

Mais do que isso, após segmentar seus consumidores uma nação deve se posicionar estrategicamente no mercado internacional, assim como as empresas. O posicionamento é a ação de projetar o produto e a imagem da empresa para ocupar um lugar diferenciado na mente do públicoalvo (Kotler \& Keller, 2006) e faz parte da estratégia da empresa. Estabelecer pontos de diferenciação é a tarefa chave do posicionamento de uma marca (Dinnie, 2008). Essa diferenciação deve-se destacar das marcas e ofertas dos consumidores, bem como deve atender às necessidades e expectativas (Ghodeswar, 2008).

Analogamente, o posicionamento de uma marcapaís faz parte da estratégia da marca-país (Brand Finance, 2015) e deriva de seus valores, o que é a parte mais complicada do processo de branding, porque o posicionamento precisa ser desafiador, diferencial e o mais importante, precisa ser traduzido aos outros públicos, e o país possui diversos stakeholders (Gilmore, 2002). Os gerentes de uma marca-país devem adotar uma abordagem mais holística quando desenvolvem sua estratégia de posicionamento, sendo que esta deve permitir que seu país se diferencie do que seus concorrentes estão oferecendo (Rojas-Méndez, 2013).

Neste ponto, é possível enxergar uma ligação com a identidade de país, pois esta reflete o que é único sobre o país e deve ser, portanto, a base de seu posicionamento. Em termos práticos, Gilmore (2002) sugere a utilização do diamante do posicionamento para posicionar uma marca-país efetivamente no cenário internacional. Este diamante contém as macrotendências, os stakeholders, os competidores e as competências essenciais. As macrotendências representam as tendências políticas, econômicas, culturais, populacionais e de estilo de vida do país. Os stakeholders abrangem os residentes e futuros residentes do país, os trabalhadores, os turistas, os investidores, os estudantes, a mídia, os governos, os compradores dos produtos nacionais. Os competidores incluem outras regiões e países. As competências essenciais envolvem os ativos físicos e humanos do país.
Uma alternativa para ajudar a desenvolver estratégias de posicionamento efetivas a fim de aumentar as vantagens competitivas do país é identificar as dimensões de sua personalidade de marca, que estão relacionadas ao fato do país possuir uma série de características humanas associadas aos consumidores e essas associações poderem afetar as intenções deles em relação a um país específico (Rojás-Mendez, Murphy \& Papadopoulos, 2013).

Uma nação que não se compromete em desenvolver um branding pró-ativo corre o risco de ser posicionada de qualquer maneira pelos seus concorrentes, tornando cada vez mais difícil o controle do seu futuro econômico (Gilmore, 2002). Para seu posicionamento ser efetivo, as nações têm que lidar não apenas com o reforço de suas dimensões e lados positivos, mas também com a redução de qualquer imagem negativa que seus consumidores possuem (Rojas-Méndez, 2013).

Além disso, o country branding pode ser usado para reposicionar um país como parte de sua estratégia de desenvolvimento econômico nacional (Mugobo \& Wakeham, 2014). Esse reposicionamento é denominado "re branding", pode ser realizado com sucesso e tem um grande potencial para as nações, sobretudo nos casos em que estas possuem um estereótipo que está aquém da realidade (Dinnie, 2008). Esse processo está diretamente relacionado com a imagem de país, pois as mudanças na imagem e nas percepções permitem que a nação se reposicione para alcançar vantagem competitiva no turismo e nos negócios (Knott, Fyall \& Jones, 2015).

A Espanha é um exemplo de país que passou por este processo de reposicionamento e foi bemsucedida (Gilmore, 2002). Entretanto, vale ressaltar que a mudança que ocorreu na Espanha e em sua imagem nacional é resultado de mudanças fundamentais em seus sistemas político, econômico e social que ocorreram em vinte anos e não apenas o resultado de campanhas de branding (Fan, 2006). Isso significa que o branding é uma ferramenta poderosa, mas que se o país não mudar suas bases econômicas, sociais e políticas, além de sua estratégia, as ações de branding não vão funcionar, principalmente aquelas ligadas à comunicação e divulgação do país internacionalmente. Portanto, os países devem compreender que o processo de branding envolve um comprometimento de longo prazo (Dinnie, 2008).

Por fim, considerando os três elementos do 
branding para países, pode-se constatar que o posicionamento do país funciona como elemento de ligação entre a identidade da marca-país e sua imagem, uma visão semelhante à de Pike (2008). Ainda, retomando e aprofundando as discussões deste tópico é possível refletir sobre essas relações e como o country branding engloba esses elementos, o que está presente na Figura 2: gerando valor para a marca-país e o denominado efeito país de origem, como visto anteriormente.

Ainda, considerando o country branding, pode-se afirmar que esse envolve desde a criação e planejamento, até a comunicação da marca-país. Essa criação e planejamento engloba o conhecimento da identidade da marca-país e de seus elementos, que por sua vez, são analisados para traçar o

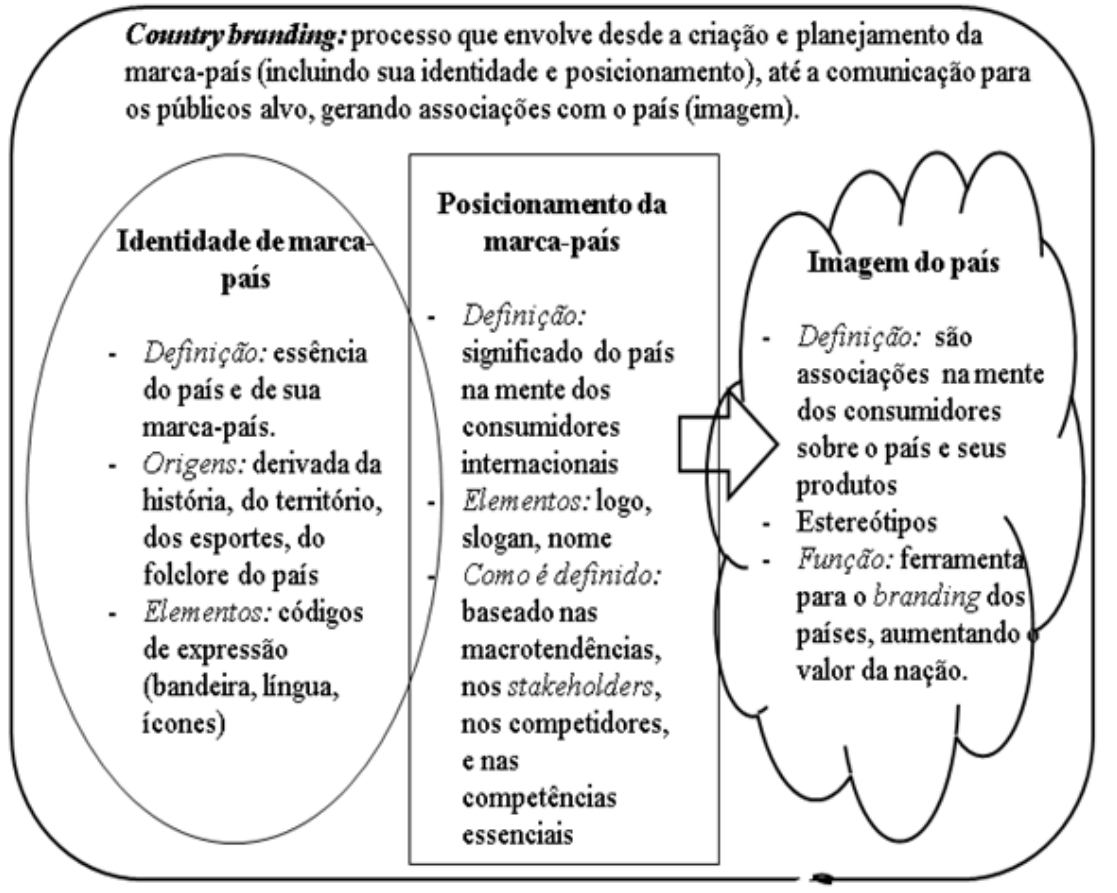

Fig. 2

Relação entre country branding identidade de marca-país, imagem de país e posicionamento da marca-país. Fonte: Elaborada pelas autoras.
Observando a Figura 2, nota-se que a identidade da marca-país é a imagem desejada do país e de sua marca, ou seja, é a imagem que os gestores de branding querem criar na mente dos consumidores internacionais. Ela é a base para o posicionamento, pois este busca diferenciar o país dos demais concorrentes e criar significado na mente dos consumidores, e a identidade é justamente a essência da nação, o que a torna única: sua história, seu território, seu povo, seus esportes, sua cultura. Assim, a estratégia de posicionamento do país, também estabelecida pelos gestores de marca-país, usa os elementos da identidade do país e sua essência (história, território, povo, esportes, cultura) para construir uma forte diferenciação na mente dos stakeholders internacionais.

O resultado desse posicionamento e como esses elementos são percebidos pelos consumidores formam suas associações, imagens em relação ao país, que podem muitas vezes ser baseadas em estereótipos. Essa imagem do país pode se mostrar uma ferramenta benéfica para o country branding, posicionamento da marca-país. Após a definição do posicionamento, os gestores de marca-país comunicam os pontos positivos e relevantes do país por meio de ações de branding. A partir dessa comunicação, os consumidores internacionais formam a imagem do país.

Enfim, são traçadas algumas considerações finais do trabalho.

\section{CONSIDERAÇÕES FINAIS}

Em um cenário internacional competitivo e dinâmico, os países estão cada vez mais sendo vistos e agindo como marcas. Deste modo, este estudo apresentou por meio de uma revisão teórica os principais conceitos relacionados à marca-país e sua gestão, buscando diferenciá-la de imagem de país e efeito país de origem, e também detalhar a gestão dessa marca, explorando suas principais diferenças em relação à gestão de marcas de produtos e serviços, seus fundamentais objetivos e seus principais elementos. 
Primeiramente, o conceito de marca-país mostrou-se relacionado, mas diferente dos conceitos de imagem de país e efeito país de origem. A marca-país deriva da cultura e dos valores da nação e está ligada a um processo gerencial, intencional e estratégico com o objetivo de diferenciar o país e seus produtos para os seus públicos-alvos. A imagem de país faz parte de um processo perceptual, é constituída pelas associações dos consumidores com o país, é como os consumidores percebem o país e suas características, sendo assim uma ferramenta para aumentar o poder da marca-país. Já o efeito país de origem ocorre quando os consumidores incorporam um estímulo do país (que pode ser derivado de sua marca-país ou de sua imagem) como um critério nas suas atitudes em relação aos produtos e serviços oferecidos por esse país.

O processo gerencial ao qual a marca-país se refere é denominado country branding. Ele engloba desde a criação até a comunicação do país e de sua marca internacionalmente e tem como objetivos fundamentais atrair turistas, estimular investimentos e impulsionar exportações, além de atrair talentos. Entretanto, ele é muito mais complexo do que para produtos e serviços, pois envolve mais stakeholders (governos, grupos industriais, empresas), mais públicos-alvos (turistas, investidores, consumidores, possíveis moradores), e deriva de várias disciplinas teóricas, como geografia política, relações internacionais, marketing.

Ainda, ele deve considerar três elementos fundamentais inter-relacionados: a identidade da marca-país, a imagem de país e o posicionamento do país e de sua marca. A primeira é a essência da nação, é a imagem que o país deseja formar na mente dos seus consumidores. Ela é fundamentada na cultura, na história e no povo e é base para o posicionamento do país no cenário internacional. O posicionamento usa os elementos da identidade (logo, slogan, nome) bem como ferramentas de comunicação a fim de diferenciar o país dos demais concorrentes e criar significado na mente dos consumidores internacionais. Como esses elementos, que revelam as características do país, são percebidos pelos consumidores internacionais constitui a imagem do país.

Assim, foi possível compreender e elucidar conceitos essenciais associados a marca-país e sua gestão, ilustrando a complexidade desta. Também foram obtidas informações importantes para os gestores de marca-país e que podem colaborar para a construção dessa marca, que é um processo contínuo.

Estudos futuros podem considerar essas definições mais claras para elaborar mensurações mais precisas de imagem de país, marca-país e efeito país de origem. Outro aspecto destacado nesse estudo são os objetivos do country branding, que podem ser direcionadores de outra lacuna teórica que pode ser solucionada em futuras investigações: como desenvolver uma marca-país competitiva para alcançar esses objetivos importantes e complexos.

Logo, novos trabalhos poderiam investigar a construção e elaboração de marcas-país, estudando casos em profundidade, realizando entrevistas com os responsáveis pelo gerenciamento dessas marcas, a fim de compreender melhor o processo, suas vantagens e desvantagens, suas etapas, para traçar seu diferencial competitivo. Outra abordagem seria mensurar o efeito país de origem precisamente com base no conceito apresentado para verificar como a marca-país e o country branding podem influenciar o comportamento dos consumidores internacionais, ou seja, como ela pode atrair turistas, investidores, compradores, moradores para o país.

\section{REFERÊNCIAS}

- $\quad$ Aaker, D. A. (1996). Building strong brands. New York: The Free Press.

- $\quad$ Aaker, D.A. (2007). Construindo marcas fortes. Porto Alegre: Bookman.

- Aharoni, Y., \& Brock, D. (2010) International business research: Looking back and looking forward. Journal of International Management, 16 (1), p. 5-15.

- $\quad$ AMA - American Marketing Association. Retrieved June 18, 2015 from https://www.ama.org/Pages/default.aspx

- $\quad$ Andina, C., Gabriela, C., \& Roxana-Denisa, S. (2015). Country-of-Origin Effects on Perceived Brand Positioning. Procedia Economics and Finance, 23, 422427.

- Anholt, S. (2006). Beyond the Nation brand: The Role of Image and Identity in International Relations. UK Foreign Office Public Diplomacy Board.

- Anholt, S. (2005). Branding nations. Brand strategy, n. 196.

- $\quad$ Anholt, S. (2007). Competitive identity: The new brand management for nations, cities and regions. New York: Palgrave Macmillan.

- Apex-Brasil (Agência Brasileira de Promoção de Exportações e Investimentos) (2017). Quem somos. 
Retrieved Aug 27, 2017 from

http://www.apexbrasil.com.br/quem-somos

- $\quad$ Blain, C., Levy, S. E., \& Ritchie, J. R. B. (2005). Destination Branding: Insights and Practices from Destination Management Organizations. Journal of Travel Research, 43, 328-338.

- Bloemer, J, Brijs, K., \& Kasper, H. (2009). The CoO-ELM model $A$ theoretical framework for the cognitive processes underlying country of origin-effects. European Journal of Marketing, 43 (1/2), 62-89, 2009.

- Brand Finance. (2015). Nation Brands 2015: The annual report of the most valuable nation brands. Retrieved May 5, 2016 from http://brandfinance.com/images/upload/brand_financ e_nation_brands_2015.pdf

- Brand Finance (2016). Nation Brands 2016: The annual report of the most valuable nation brands. retrieved Aug 15, 2017 from http://brandfinance.com/knowledgecentre/reports/brandfinance-nation-brands-2016/

- Brijs, K., Bloemer, J., \& Kasper, H. (2011). Countryimage discourse model: unraveling meaning, structure, and function of country images. Journal of Business Research, 64 (12), 1259-1269.

- Castro, R. M., \& Giraldi, J. M. E. (2012). Processo de desenvolvimento e gestão de marca-país: um estudo sobre a Marca Brasil. Revista Turismo Visão e Ação Eletrônica, Vale do Itajaí, 14 (2), 164-183.

- Chernatony, L., McDonald, M., \& Wallace, E. (2011). Creating Powerful Brands. 4ed. Oxford: ButterworthHeinemman.

- Churchill, G. A., Brown, T. J. \& Suter, T. A. (2011). Pesquisa básica de marketing. 7ed. São Paulo: Cengage Learning.

- Crescitelli, E., \& Giraldi, J. M. E. (2009). Países como marcas: dificuldades no desenvolvimento de marcapaís. FACEF Pesquisa, 12 (3).

- Dinnie, K. (2008). Nation branding: Concepts, issues, practice. 1 ed. Oxford: Routledge.

- Dinnie, K. (2015). Nation branding: Concepts, issues, practice. 2 ed. Oxford: Routledge.

- Dinnie, K., Melewar, T. C.., Seidenfuss, K. U., \& Musa, G. (2010). Nation branding and integrated marketing communications: an ASEAN perspective. International Marketing Review, 27 (4), 388 - 403.

- Domeisen, N. (2003). Is there a case for national branding? The Magazine of the international trade centre - International Trade Forum. Retrieved June 18, 2015 from http://www.tradeforum.org/ls-There-aCase-for-National-Branding/

- Dwyer, L., \& Kim, C. (2003). Destination Competitiveness: Determinants and Indicators. Current Issues in Tourism, 6 (5), 369-414.

- Durand, A. (2016). Building a better literature review: Looking at the nomological network of the country-of- origin effect. Canadian Journal of Administrative Sciences/Revue Canadienne des Sciences de l'Administration, 33 (1), 50-65.

- Elliot, S., Papadopoulos, N., \& Kim, S. S. (2011). A integrative model of place image: exploring relationships between destination, product, and country images. Journal of Travel Research, 50, 520534.

- $\quad$ Fan, Y. (2006). Banding the nation: What is being branded? Journal of Vacation Marketing, 12(1), 5-14.

- Fan, Y. (2010). Branding the nation: Towards a better understanding. Place Branding and Public Diplomacy, 6(2), 97-103

- Fetscherin, M. (2010). The determinants and measurement of a country brand: The country brand strength index. International Marketing Review, 27(4), 466-479.

- Gilmore, F. (2002). A country, can it be repositioned? Spain, the success story of country branding. Journal of Brand Management, 9(4), 281-293.

- Giraldi, J. M. E. (2016). Evaluation of the impact of Brazil's sustainability on the behavioral intentions of stakeholders toward the country. Evaluation and Program Planning, 54, p. 135-143.

- Ghodeswar, B.M. (2008). Building brand identity in competitive markets: a conceptual model. Journal of product \& brand management, 17 (1), 4-12.

- Groonros, C. (2004). Marketing: gerenciamento e serviços. RJ: Campus.

- Hakala, U., Lemmetyinen, A. \& Kantola, S-P. (2013). Country image as a nation-branding tool. Marketing Intelligence \& Planning, 31(5), 538-556.

- Hakala, U. \& Lemmetyinen, A. (2011). Co-creating a nation brand "bottom up. Tourism Review, 66 (3), p. 14 -24 .

- Herget, J., Petrů, Z., \& Abrhám, J. (2015). City branding and its economic impacts on tourism. Economics and Sociology, 8 (1), 119-126.

- Heslop, L. A., Papadopoulos, N., Dowdles, M., Wall, M. \& Compeau, D. (2004). Who controls the purse strings: A study of customers' and retail buyers' reactions in na America's FTA environment. Journal of Business Research, 57 (10), 2004.

- Hurn, B. J. (2016). The role of cultural diplomacy in nation branding. Industrial and Commercial Training, 48 (2), p. $80-85$.

- Kapferer, J. (2001). Reinventing the brand. London: Kogan Page.

- Keller, K. L. (1993). Conceptualizing, measuring and managing customer based brand equity. Journal of Marketing, 57(1), 1-22.

- Keller, K. L. \& Machado, M. (2006). Gestão Estratégica de Marcas. São Paulo: Pearson Prentice Hall. 
- $\quad$ Keller, K. L. Brand Synthesis: The Multidimensionality of Brand Knowledge (2003). Journal of Consumer Research, 29 (4), 595-600.

- Keller, K. L. (2009). Building strong brands in a modern marketing communications environment. Journal of Marketing Communications, 15 (2-3), 139-155.

- Knott, B., Fyall, A \& Jones, I. (2015). The nation branding opportunities provided by a sport megaevent: South Africa and the 2010 FIFA World Cup. Journal of Destination Marketing \& Management, 4 (1), 46-56.

- Kilduff, K. \& Núñez-Tabales, J. M. (2014). Country image management: Brand Spain in the United States. Regional and Sectoral Economic Studies, 14 (2), 5-16.

- Kimpakorn, N. \& Tocquer, G. (2010). Service Brand Equity and Employee Brand Commitment. Journal of Services Marketing, 24 (5), 378-388.

- Kotler, P., \& Gertner, D. (2002). Country as brand, product, and beyond: A place marketing and brand management perspective. J Brand Manag, 9(4), 249261.

- Kotler, P., \& Gertner, D. (2004). O estratégico marketing de lugares (Dossiê). HSM Management, 44, 2004.

- $\quad$ Kotler, P., Haider, D. H. \& Rein, I. J. (1993) Marketing places: attracting investment, industry, and tourism to cities, states, and nations. New York: Free Press.

- Kotler, P., Haider, D. H. \& Rein, I. J. (2006). Marketing de lugares: como conquistar crescimento de longo prazo na América Latina e no Caribe. São Paulo: Prentice Hall.

- Kotler, P. \& Keller, K. L. (2006). Administração de marketing. São Paulo: Pearson Prentice Hall.

- Kotler, F. \& Pfoertsch, W. (2008). Gestão de marcas em um mercado B2B. Porto Alegre: Bookman.

- Laroche, M., Papadopoulos, N., Heslop, L. A.\& Mourali, $M$. (2005).The influence of country image structure on consumer evaluations of foreign products, International Marketing Review, 22 (1), 96-115.

- Mamuti, A. \& Özgüner, D. (2014). Nation branding as a means of attracting FDI: The case of Bosnia and Herzegovina. International Journal of Business and Globalisation, 13 (2), 197-208.

- Mariutti, F. G. \& Giraldi, J. M. E. (2012). Análise da imagem do Brasil por meio do Anholt Nation Branding Index. Turismo: Visão e Ação (Online), 14, 67-81.

- Matiza, T. \& Onu, O. A. (2014). The Case for Nation Branding as an Investment Promotion Methodology for African Nations: A Literature-Based Perspective. Mediterranean Journal of Social Sciences, 5 (3), 262272.

- Mugobo, V. V. \& Wakeham, M. (2014). Re-Branding Zimbabwe: A Transformative and Challenging Process. Mediterranean Journal of Social Sciences, 5 (27), 298310.
- $\quad$ Nikolova, M.S. \& Hassan, S. S. (2013). Nation branding effects on retrospective global evaluation of past travel experiences. Journal of Business Research, 66 (6), 752758.

- O'Shaughnessy, J. \& O’Shaughnessy, N. J. (2000). Treating the Nation as a Brand: Some Neglected Issues. Journal of Macromarketing, 20 (1), 56-64.

- Papadopoulos, N. \& Heslop, L. A. (2002). Country equity and country branding: Problems and prospects. Brand Management, 9(4), 294-314.

- Papadopoulos, N., Hamzaoui-Essoussi, L., \& El Banna, A. (2016). Nation branding for foreign direct investment: an Integrative review and directions for research and strategy. Journal of Product \& Brand Management, 25 (7), 615-628.

- Pappu, R. \& Quester, P. G. (2010) Country equity: Conceptualization and empirical evidence. International Business Review, 19 (3), 276-291.

- Pappu, R., Quester, P. G. \& Cooksey, R. W. (2005). Consumer-based brand equity: improving the measurement-empirical evidence. Journal of Product \& Brand Management, 14 (3), 143-154.

- Pike, S. D. (2008). Destination marketing: an integrated marketing communication approach. Oxford: Elsevier.

- Publication Manual of the American Psychological Association (2010). Publication Manual of the American Psychological Association. Retrieved $24 \mathrm{Mar}$, from http://lumenjournals.com/wpcontent/uploads/2017/08/APA6thEdition.pdf

- Rojas-Méndez, J.I. (2013). The nation brand molecule. Journal of Product \& Brand Management, 22(7), 462472.

- Rojas-Méndez, J.I., Murphy, S. A. \& Papadopoulos, N. (2013). The U.S. brand personality: a sino perspective. Journal of Business Research, 66 (8), 1028-1034.

- Roy, D. \& Banerjee, S. (2014). Identification and measurement of brand identity and image gap: a quantitative approach. Journal of Product \& Brand Management, 23 (3), 207-219.

- Shimp, T.A. (2009). Comunicação integrada de marketing: propaganda e promoção. 7. ed. Porto Alegre: Bookman.

- Sirr, G., Garvey, J. \& Gallagher, L. (2012). A quantitative approach to guiding the promotional efforts of IPAs in emerging markets. International Business Review, 21(4), 618-630.

- Sun, Q., Paswan, A. K., \& Tieslau, M. (2016). Country Resources, Country Image, and Exports: Country Branding and International Marketing Implications. Journal of Global Marketing, 233-246.

- Wang, C.L., Li, D., Barnes, B.R., \& Ahn, J. (2012). Country image, product image and consumer purchase intention: evidence froam an emerging economy. International Business Review, 21 (6), 1041-1051. 
- $\quad$ WTTC (World Travel and Tourism Council). (2015). Global Benchmarking Report 2015. Retrieved May 5, 2016 from http://www.wttc.org/research/economicresearch/benchmark-reports/
- Zeugner-Roth, K. P., \& Diamantopoulos, A. (2010). Advancing the country image construct: Reply to Samiee's (2009) commentary. Journal of Business Research, 63 (4), 446-449.

\section{SOBRE AS AUTORAS}

- Maria Gabriela Montanari Doutoranda em Administração de Organizações na Universidade de São Paulo, na linha de pesquisa de Planejamento, Inteligência de Mercado e Relações Contratuais. Possui graduação em Matemática Aplicada a Negócios pela Universidade de São Paulo (2012) e mestrado em Administração de Organizações pela Universidade de São Paulo (2015). Tem particular interesse pela área de Marketing, atuando principalmente nos seguintes temas: marketing de lugares, matemática aplicada.E-mail: mariagabrielamontanari@yahoo.com.br.ORCID:0000-0002-0487-8369

- Janaina de Moura Engracia Giraldi Professora Associada da Faculdade de Economia, Administração e Contabilidade de Ribeirão Preto (FEA-RP), Universidade de São Paulo (USP). Possui Graduação em Administração de Empresas pela Universidade de São Paulo (1998), Especialização em Master of Science in Marketing pela KULeuven (Bélgica) (2002), Mestrado em Administração pela Universidade de São Paulo (2004), Doutorado em Administração pela Universidade de São Paulo (2006) e Livre Docência em Administração (especialidade Marketing) pela Universidade de São Paulo (2014). Tem experiência na área de Administração, com ênfase em Marketing, atuando principalmente nos seguintes temas: Imagem e Marca de Países, Marketing de Lugares, Comportamento do Consumidor, Pesquisa de Marketing, Marketing de Serviços, Planejamento e Estratégia em Marketing. EditoraChefe da RACEF - Revista de Administração, Contabilidade e Economia da Fundace desde 2014. Revisora de artigos de periódicos e congressos nacionais e internacionais da área de marketing $e$ revisora ad hoc de agências de fomento à pesquisa (CAPES, CNPq, FAPESP). E-mail: jgiraldi@usp.br. ORCID: 0000-0003-3086-7134 


\title{
A theoretical study on country brand and its management
}

\author{
Maria Gabriela Montanari and Janaina de Moura Engracia Giraldi
}

Universidade de São Paulo (USP), Ribeirão Preto, SP, Brazil.

\begin{tabular}{l}
\hline ARTICLE DETAILS \\
\hline Article history: \\
Received: 13 June 2017 \\
Reviewed: 27 February 2018 \\
Accepted: 28 April 2018 \\
Available online: 01 May 2018 \\
Double Blind Review System \\
Scientific Editor \\
Renata Galhanone \\
\hline Keywords: \\
Country Brand \\
Country Branding \\
Country Image
\end{tabular}

\begin{abstract}
This paper presents a theoretical study in order to clarify the concept of country brand, differentiating it from country image and country of origin effect, and also detail its management, exploring its complexity and differences from the brand management of products and services. Based on the literature, we found that the country brand is derived from a management process, the country branding, which seeks to differentiate between the nation and its offerings in the international market based on their culture. This process involves since the creation of the country brand to its communication to the various target audiences, is more complex than for goods and services, and should consider the elements of country's identity, positioning and image. The country image is often the focus of branding actions because consists of the associations of the country that international consumers hold in their memory and is considered a tool that can increase the power of the country brand. Thus, it was possible to contribute both to the country brand theory and management, and to governments by providing relevant information to help in defining strategic actions in relation to the country brand and its image.
\end{abstract}

(C) 2018 Internext | ESPM. All rights reserved!

Para citar este artigo:

Montanari, M. G. e Giraldi, J. M. E., (2018) Um estudo teórico sobre marca-país e sua gestão. InternextRevista Eletrônica de Negócios Internacionais, 13 (2), 14-29. DOI: http://dx.doi.org/10.18568/19804865.13214-29

Para acessar este artigo: http://dx.doi.org/10.18568/1980-4865.13214-29 